\title{
Introduction of electric vehicles in Peru: Potential contribution to carbon emission reduction.
}

\author{
Dr. Serapio Quillos-Ruiz ${ }^{1}$, Nelver Escalante-Espinoza ${ }^{1}$, Johnny Nahui-Ortiz, Ph.D. ${ }^{2}$ \\ 1'Universidad Nacional del Santa, Peru, s_quillos@hotmail.com, cfpnjee@yahoo.es \\ ${ }^{2}$ National University of Engineering, Peru, jnahuio@uni.edu.pe
}

\begin{abstract}
Electric Vehicles are about to enter the Peruvian market. There is expectation with regard to their potential contribution to carbon emission reduction. Small vehicles run usually on gasoline. There is also a number of vehicles that are now running on Liquefied Petroleum Gas (LPG) or Natural gas which originally were designed to run on gasoline.

The substitution of gasoline with LPG or Natural Gas already has contributed to carbon emission reduction and also, equally important, provided the end user with cost savings. The objective of the paper is to assess how electric vehicles might contribute to the reduction of carbon emissions.

Electric vehicles are assumed to be free of carbon emissions in their operation; however, the electricity used for operation of electric vehicles may not be free of carbon emissions in its generation. Thermal power plants have increased their share in the electricity production mix of Peru and last year accounted for nearly half of total production.

A total of 26'666,537 $\mathrm{tCO} / \mathrm{yr}$ are emitted due to the use of fossil fuels in the transportation sector. Nearly 55\% of those comes from the use of diesel oil. Therefore, careful evaluation is required in order to establish a realistic expectation about carbon emission reduction due to the potential introduction of electric vehicles in the local market.

For illustration purposes, substitution rates of 2\%, 5\%, 3\%, and $5 \%$ are considered for natural gas, gasoline motor, liquefied petroleum gas, and gasoline/ethanol, respectively. By doing so, a total of 348,437 $\mathrm{tCO}_{2} / \mathrm{yr}$ could be avoided.

This means that a $15 \%$ penetration of electric vehicles would lead to a reduction of $59.70 \%$ when compared to the use of Compressed Natural Gas (CNG), LPG, Gasoline Motor, and Gasoline/Ethanol, but only a reduction of $0.78 \%$ if compared to total current carbon emissions.
\end{abstract}

Keywords-Transportation Sector, Electricity Mix, Carbon Emissions, Electric Vehicles, Environmental Management.

\section{INTRODUCTION}

The transportation sector in Peru and in other countries as well is the main source of carbon dioxide emissions. Last decade, some users started to substitute gasoline with liquified petroleum gas basically due to a cost difference between these two fuels. Nevertheless, carbon dioxide emissions were assumed to be reduced to some extent. More recently, additional users have replaced gasoline with compressed natural gas, again basically due to a cost difference between these two fuels. Nevertheless, carbon dioxide emissions were assumed again to be reduced to some extent.

Digital Object Identifier (DOI):

http://dx.doi.org/10.18687/LACCEI2020.1.1.265

ISBN: 978-958-52071-4-1 ISSN: 2414-6390
The research group is interested in finding out to what extend the introduction of electric vehicles into the local market may or not contribute to reduce significantly carbon dioxide emissions.

\section{BACKGROUND}

In Ref. [1], approximately $70 \%$ of the total potential electric vehicle (PEV) model sales have lower all-electric ranges and battery capacity than average in the top 5 provinces that have sold the most battery electric vehicles (BEVs) or plug-in hybrid electric vehicles (PHEVs). From 2011 to 2017, 682,047 PEVs have been sold in the 5 provinces, with 18.3 billion electric vehicle kilometers traveled (VKT). 3.0 TWh of electricity were consumed, reducing gasoline consumption by 1.6 billion liters and $\mathrm{CO}_{2}$ emissions by 611,824 tons. Approximately $70 \%$ of the total gasoline replacement and $80 \%$ of the total $\mathrm{CO}_{2}$ emissions reduction were contributed by BEVs.

In Ref. [2], the impact that electric vehicles fuelled with the average energy mix, hydrogen vehicles (HyVs) fuelled with hydrogen from electrolysis from the regular energy mix, $\mathrm{HyVs}$ fuelled with hydrogen produced through wind power, energy efficient combustion-powered vehicle (CVs), electric vehicle (EVs) fueled with wind power and energy efficient metro light railway (metro) travel have on summer heat island intensity (SHII) and $\mathrm{CO}_{2}$-emissions is analyzed. The lowest SHII mitigation effect was found for a replacement of CVs with fuel efficient diesel cars while hydrogen cars that are fuelled with hydrogen generated from the average electricity mix even leads to higher SHII and higher $\mathrm{CO}_{2}$ emissions. The largest SHII mitigation effect was found for a scenario where conventional vehicles are replaced with energy efficient metro travel. The $\mathrm{CO}_{2}$ saving potential is highest for EVs which are powered with electricity generated from wind turbines, closely followed by HyVs that are fuelled with hydrogen generated from electrolysis of water using wind electricity. The paper helps policymakers and consumers to make the right choices when it comes to environmentally friendly mobility options.

In Ref. [3], electric vehicles are an emerging technology with significant potential for reducing carbon dioxide emissions. Yet strategies to minimize carbon dioxide emissions by strategically charging during different times of day have not been rigorously explored. Optimized schedules of plug-in electric vehicle charging for standard and vehicleto-grid use were compared with pre-timed charging schedules to characterize the potential for carbon dioxide emission reductions across charging characteristics, regional driving,

18 $^{\text {th }}$ LACCEI International Multi-Conference for Engineering, Education, and Technology: "Engineering, Integration, and Alliances for a Sustainable Development" "Hemispheric Cooperation for Competitiveness and Prosperity on a Knowledge-Based Economy", July 27-31, 2020, Virtual Edition. 
and marginal energy generation trends. It was found that optimized charging can reduce carbon dioxide emissions over pre-timed charging by as much as $31 \%$ for standard use and $59 \%$ for vehicle-to-grid use. However, some scenarios of vehicle-to-grid participation were found to increase carbon dioxide emissions by up to $396 \mathrm{~g}$ carbon dioxide per mile by displacing stored energy from more carbon-intense energy generation periods. Results also indicate that plug-in electric vehicle charging emissions can vary widely for a given energy efficiency rating. Current energy efficiency ratings may lead to incorrect assumptions of plug-in electric vehicles emissions compared to conventional gasoline vehicles due to varying regional and temporal emissions. To coincide with the push for lower greenhouse gas emissions from transportation, charging times for plug-in electric vehicles should target periods where charging promotes carbon dioxide reductions, and electric vehicle energy efficiency ratings should be reconsidered in order to promote sustainable plug-in electric vehicle use moving forward.

In Ref. [4], this work evaluates the effects of the replacement of engine-powered vehicles by electric vehicles on carbon dioxide $\left(\mathrm{CO}_{2}\right)$ emissions and energy consumption. The scenarios were designed considering favorable and unfavorable conditions for electricity production from a clean source, thus influencing the $\mathrm{CO}_{2}$ emission factor adopted. The simulations showed that the electric energy consumption by the electric vehicles is about four times lower than fuel energy consumption by the conventional vehicles undergoing a standard test schedule. At the end of the period considered the electric vehicles will produce lower $\mathrm{CO}_{2}$ emissions than the conventional vehicle fleet by a factor of 10 , even considering the most unfavorable scenario of electric power generation.

In Ref. [5], in this framework, a vehicle fleet model was developed which combines a bottom-up consumer demand model with a dynamic stock-flow approach. Special emphasis is thereby given to different electric power-trains and synthetic gaseous fuels based on the power-to-gas technology. In detail, two different main scenarios are developed and, in addition, the impact of different carbon dioxide taxation levels of fossil fuels on the vehicle fleet structure are analyzed. The scenario results reveal a broad range of possible future vehicle fleet structures. In the short to medium timeframe, the internal combustion engine dominates the fleet as a result of efficiency improvements and an increased use of natural gas as automotive fuel.

In Ref. [6], Malta is committed to reaching 5000 Battery Electric Vehicles (BEVs) on the road by 2020 in line with its European Union (EU) obligations. A scheme was recently announced aimed at encouraging ownership of electric vehicles, reducing the number of old motor vehicles from the road and thus reducing emissions. The scheme comprises a grant of $€ 4000$ to persons registering an electric vehicle, increasing to $€ 5000$ in the case of persons registering for an electric vehicle while at the same time de-registering their own vehicle, if it is at least 10 years old. The unique problem in Malta is that as much as $98 \%$ of electricity generation is produced from combustion of fossil fuels, mainly heavy fuel oil and diesel oil. The combustion of fossil fuels results in significant environment impacts, particularly in emission of Carbon Dioxide $\left(\mathrm{CO}_{2}\right)$. This paper determines that the benefits of driving BEVs in Malta depend on the electricity mix at the point of charging, and with the existing electricity mix. Three scenarios are analyzed, and in the case where the energy mix is dependent on natural gas, this study shows that the $\mathrm{CO}_{2}$ emissions of BEVs are considerably less than for either hybrid or vehicle powered by conventional fuel.

In Ref. [7], an interesting aspect presented is the calculation of the Greenhouse Gases (GHG) content of electricity traded between Countries, affecting the carbon intensity (CI) of the electricity consumed at national level. The amount and CI of imported electricity is a key aspect: a Country importing electricity from another Country with a lower CI of electricity will lower, after the trade, its electricity CI, while importing electricity from a Country with a higher CI will raise the $\mathrm{CI}$ of the importing Country. In average, the CI of electricity used in EU at low voltage in 2013 was 447 $\mathrm{gCO}_{2} \mathrm{eq} / \mathrm{kWh}$, which is the $17 \%$ less compared to 2009 .

In Ref. [8], plug-in hybrid electric vehicles (PHEVs) have the potential to decrease greenhouse gas emissions given certain power generation profiles. The adoption of PHEVs is associated with significant social, economic, environmental, and health benefits. However, most researchers in literature generally estimate emissions using national averages of emission data. The purpose of this paper is to address this gap. Our study results reiterated that to reduce $\mathrm{CO}_{2}$ emissions considerably, promotion of PHEVs should be integrated with renewable electricity generation options.

In Ref. [9], this paper aims to analyze how the pace of Battery Electric Vehicles transition and driving behavior of Plugged in Hybrid Electric Vehicles users can impact the Green House Gas emissions reduction performance of the UK transport sector in meeting the carbon targets by 2050. A reference model for different types of vehicle classes is developed to determine the emissions contributed. The growth of each vehicle class, improvements in efficiency of Electric Vehicles and low carbon fuel targets are projected until the year 2050. Scenario-based models are then developed to analyze how varying the pace of Battery Electric Vehicle transition and hybrid car user driving behavior would impact the emissions reduction performance. The results of the paper show that the current pace of Battery Electric Vehicle adoption is insufficient for the UK transport sector to achieve the 4th to 7th carbon budgets, due to the slow reduction in Internal Combustion Engine Vehicles. For the 8th and final carbon budgets, emissions may still exceed the carbon budget despite transiting to Electric Vehicles if hybrid car users continue to drive on gasoline modes.

In Ref. [10], the majority of previous studies examining life cycle greenhouse gas (LCGHG) emissions of battery electric vehicles (BEVs) have focused on efficiency-oriented vehicle designs with limited battery capacities. However, two dominant trends in the US BEV market make these studies 
increasingly obsolete: sales show significant increases in battery capacity and attendant range and are increasingly dominated by large luxury or high-performance vehicles. In addition, an era of new use and ownership models may mean significant changes to vehicle utilization, and the carbon intensity of electricity is expected to decrease. Thus, the question is whether these trends significantly alter our expectations of future BEV LCGHG emissions.

\section{FuELS USED AND CARBON EMISSIONS IN THE TRANSPORTATION SECTOR}

In Peru, total energy consumption accounted for 846, 324 $\mathrm{TJ}$ in 2017. Energy consumption in the transportation sector represents $44.7 \%$ while energy consumption in the industry and mining sector accounts for $27.2 \%$ and in the residential, commercial and public sector accounts for $25.2 \%$.

Such a high share of the transportation sector within the total energy consumption reveals potential inefficiencies associated with the presence of old transportation units, a wide-range mix of light and heavy transportation units and complex traffic conditions in crowed locations.

Table I shows energy consumption by sectors in 2017.

TABLE I. ENERGY CONSUMPTION BY SECTORS

\begin{tabular}{|l|c|c|}
\hline \multicolumn{1}{|c|}{ SECTOR } & TJ & $\%$ \\
\hline Transportation & 378042 & $44.7 \%$ \\
\hline Residential, Commercial and Public & 213344 & $25.2 \%$ \\
\hline Industry and Mining & 230334 & $27.2 \%$ \\
\hline Agroindustrial and Fishery & 9299 & $1.1 \%$ \\
\hline Non Energy TOTAL & 15305 & $1.8 \%$ \\
\hline \multicolumn{1}{|c|}{ TOT } & 846324 & $100.0 \%$ \\
\hline
\end{tabular}

Source: Balance Nacional de Energía (Ref. 12)

Energy consumption has experience major changes over the year within the country. In former times, Diesel Oil and Gasoline were basically the only players in the transportation sector.

LPG was introduced around the year 2000, mainly in order to partially substitute the use of gasoline in small cars, based on a lower price competition.

Commercial light cars originally designed for running under gasoline, can be locally converted in order to run under LPG. The cost of a conversion kit for that purpose is about 1500 Peruvian soles.

LPG cost about 1.60 Peruvian soles per liter. Also, LPG supply can be reasonably found in several regions of the country and it is not considered to alter in any significant way the original operation of the vehicle.

A few years later, around 2006, CNG was introduced, also mainly in order to partially substitute the use of both gasoline and LPG. However, LPG is not available in all the regions of the country. Moreover, $\mathrm{CNG}$ is only available in rather few regions of the country.
Similar to the conversion from gasoline to LPG, light vehicles can also be locally converted to run under compressed natural gas. The cost of a conversion kit for that purpose is about 2700 Peruvian soles. CNG cost about 1.50 Peruvian soles per standard cubic meter.

LPG supply can be considered limited and it is not available in several regions of the country and, as opposed to LPG, it is considered to alter in certain way the original operation of the vehicle.

As a part of the introduction of CNG into the local market a particular financing incentive was designed by local Financial Corporation for Development (COFIDE). According to such financing program, a cab driver would be charged an extra cost at the time of purchasing CNG for its vehicle in order to pay for a loan that was granted to finance the conversion from gasoline to CNG.

The success of the initial program encouraged COFIDE to consider extending the scope of the loan in order to finance purchasing of a new vehicle.

In the early 2006, only two CNG fuel stations were available in the main city of the country, and the demand for CNG supply was growing at an accelerated pace. Nowadays there are several CNG fuel stations locally available.

Natural gas supply for CNG fuel stations comes from far away through a 700-km long pipeline which brings also some concerns about energy security aspects. Also, in a few cities natural gas is supply in the form of compressed natural gas and even liquefied natural gas (LNG).

However, prices of natural gas delivered by pipeline can be as half as prices of natural gas delivered by tanks in the form of CNG or LNG. Due to local prices of gasoline, $\mathrm{CNG}$ and LNG prices can still be competitive to some extent in some areas.

At present, the country has only one natural gas pipeline that crosses over jungle, highland, and coastal areas. It remains unclear whether more pipelines may be built in the future. Natural gas production costs seem to be rather lower than in nearby countries and there is the perception that its reserves may last for quite a few years even though the country has been exporting natural gas for about a decade by now.

It is important to highlight that in the last few years, there has been a competition among gasoline, LPG and CNG as a fuel for small cars; however, an alternative to directly substitute consumption of diesel oil has not been addressed.

Nowadays, commercial gasoline has taken the form of a blended fuel that is composed by gasoline and a $7.8 \%$ of ethanol. Also, commercial diesel oil has taken the form of a blended fuel that is composed by diesel oil and a $5 \%$ of biodiesel.

Figure 1 shows energy consumption evolution in the transportation in Peru for the period 2000-2017. 


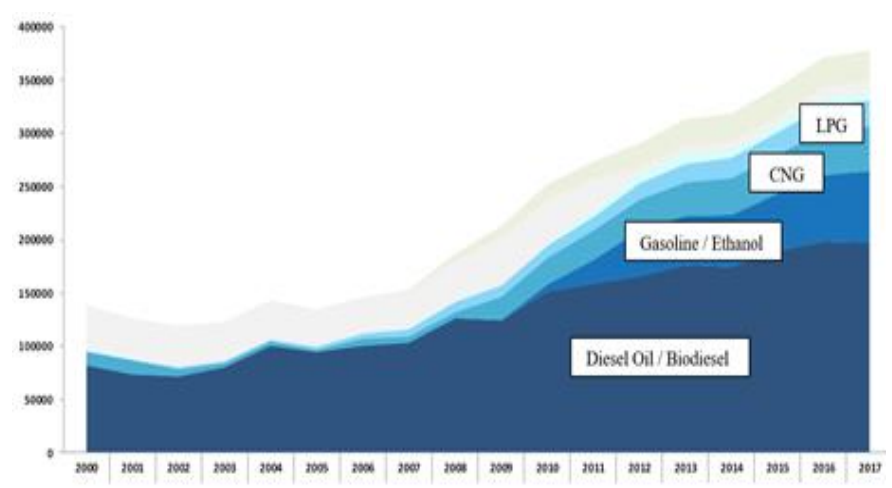

Figure 1: Evolution of energy consumption (in TJ) in the transportation sector of Peru (2000-2017).

Source: Balance Nacional de Energía (Ref. 12)

A total amount of $378,042 \mathrm{TJ} / \mathrm{yr}$ is consumed in the transportation sector. Several fossil fuels are used in the country including compressed natural gas $(\mathrm{CNG})$, liquefied petroleum gas (LPG), gasoline motor, gasoline/ethanol, fuel, oil, and aviation fuel. By far, diesel oil is the major player in terms of energy consumption for transportation. Diesel oil share represents more than $52 \%$ of total energy consumption. Gasoline is the second fuel in importance and its consumption accounts for $17.7 \%$ while natural gas represents $7.6 \%$ and liquefied petroleum gas represents $6.2 \%$ of total energy consumption in the transportation sector.

Is should also be pointed out that a large fraction of the diesel oil that is consumed within the country is imported. Therefore, there is always the concern about international affairs with regard to fuel supply and particularly at what price. Gasoline is produced locally and it has several categories that include octane ratings of 84, 90, 95, and 97. Usually old units tend to run on gasoline rated as 84 while very new units tend to run on gasoline rated as 95. Thus, gasoline prices may range from 13 to 17 Peruvian soles per gallon.

Also, more recently, electricity is also used in the transportation sector by the local subway that operates in a short distance circuit of the city of Lima.

Table II shows energy consumption by type of fuel in 2017.

TABLE II. ENERGY CONSUMPTION BY TYPE

\begin{tabular}{|c|c|c|}
\hline ENERGY FUEL & TJ & $\%$ \\
\hline Natural Gas & 28555 & $7.6 \%$ \\
\hline Electricity & 191 & $0.1 \%$ \\
\hline Gasoline Motor & 11485 & $3.0 \%$ \\
\hline Fuel Oil & 7298 & $1.9 \%$ \\
\hline LPG & 23518 & $6.2 \%$ \\
\hline Aviation & 42621 & $11.3 \%$ \\
\hline Gasoline/Ethanol & 66986 & $17.7 \%$ \\
\hline Diesel Oil & 197389 & $52.2 \%$ \\
\hline TOTAL & 378043 & $100.0 \%$ \\
\hline
\end{tabular}

Source: Balance Nacional de Energía (Ref. 12)

As mentioned before, consumption of diesel oil in the transportation sector has been growing exponentially, and thus, it is expected that carbon dioxide emissions have also been growing at the same pace.

\section{A. Natural Gas (CNG)}

According to Ref. [11], natural gas has a carbon dioxide factor equal to $15.3 \mathrm{tC} / \mathrm{TJ}$ which means $56.1 \mathrm{tCO}_{2} / \mathrm{TJ}$. Annual consumption of natural gas in the transportation sector accounted for 28,555 TJ. Then, carbon dioxide emissions due to the use of natural gas in vehicles reached 1 ' $601,936 \mathrm{tCO}_{2} / \mathrm{yr}$.

\section{B. Liquefied Petroleum Gas (LPG)}

According to Ref. [11], liquefied petroleum gas has a carbon dioxide factor equal to $17.2 \mathrm{tC} / \mathrm{TJ}$ which means 63.1 $\mathrm{tCO}_{2} / \mathrm{TJ}$. Annual consumption of liquefied petroleum gas in the transportation sector accounted for 23,518 TJ. Then, carbon dioxide emissions due to the use of liquefied petroleum gas in vehicles reached 1'483,202 $\mathrm{tCO}_{2} / \mathrm{yr}$.

\section{Gasoline Motor}

According to Ref. [11], gasoline has a carbon dioxide factor equal to $18.9 \mathrm{tC} / \mathrm{TJ}$ which means $69.3 \mathrm{tCO}_{2} / \mathrm{TJ}$. Annual consumption of gasoline in the transportation sector accounted for 11,485 TJ. Then, carbon dioxide emissions due to the use of gasoline in vehicles reached 795,911 $\mathrm{tCO}_{2} / \mathrm{yr}$.

\section{Gasoline/Ethanol}

In this case, it is estimated that carbon dioxide factor is also equal to $18.9 \mathrm{tC} / \mathrm{TJ}$ which means $69.3 \mathrm{tCO}_{2} / \mathrm{TJ}$. Annual consumption of gasoline/ethanol in the transportation sector accounted for 66,986 TJ. Then, carbon dioxide emissions due to the use of gasoline/ethanol in vehicles reached 4'642,130 $\mathrm{tCO}_{2} / \mathrm{yr}$.

\section{E. Fuel Oil}

According to Ref. [11], fuel oil has a carbon dioxide factor equal to $21.1 \mathrm{tC} / \mathrm{TJ}$ which means $77.4 \mathrm{tCO}_{2} / \mathrm{TJ}$. Annual consumption of fuel oil in the transportation sector accounted for 7,298 TJ. Then, carbon dioxide emissions due to the use of fuel oil in vehicles reached 564,622 $\mathrm{tCO}_{2} / \mathrm{yr}$.

\section{F. Diesel Oil}

According to Ref. [11], diesel oil has a carbon dioxide factor equal to $20.2 \mathrm{tC} / \mathrm{TJ}$ which means $74.4 \mathrm{tCO}_{2} / \mathrm{TJ}$. Annual consumption of diesel oil in the transportation sector accounted for 197,389 TJ. Then, carbon dioxide emissions due to the use of diesel oil in vehicles reached 14'619,945 $\mathrm{tCO}_{2} / \mathrm{yr}$.

\section{G. Aviation Fuel}

In this case, it is estimated that carbon dioxide factor is also equal to $18.9 \mathrm{tC} / \mathrm{TJ}$ which means $69.3 \mathrm{tCO}_{2} / \mathrm{TJ}$. Annual consumption of aviation fuel in the transportation sector accounted for 42621 TJ. Then, carbon dioxide emissions due 
to the use of gasoline/ethanol in vehicles reached 2'953,635 $\mathrm{tCO}_{2} / \mathrm{yr}$.

\section{H. Electricity}

In this case, it is estimated that carbon dioxide factor is equal to $27.0 \mathrm{tCO}_{2} / \mathrm{TJ}$. It has been considered that vehicles running on internal combustion engines may have an efficiency of $35 \%$ while electric vehicles may have an efficiency of $90 \%$. That is, electric vehicles are more efficient than vehicles running con internal combustion engines by a factor of 2.57.

Annual consumption of electricity in the transportation sector accounted for $191 \mathrm{TJ}$. Then, carbon dioxide emissions due to the use of electricity in transportation reached 5,157 $\mathrm{tCO}_{2} / \mathrm{yr}$.

Table III shows carbon dioxide emissions by type of fuel in 2017.

\begin{tabular}{|c|c|c|}
\hline ENERGY FUEL & $\mathrm{MtCO}_{2}$ & $\%$ \\
\hline Natural Gas & 1.60 & $6.0 \%$ \\
\hline Electricity & 0.01 & $0.0 \%$ \\
\hline Gasoline Motor & 0.80 & $3.0 \%$ \\
\hline Fuel Oil & 0.56 & $2.1 \%$ \\
\hline LPG & 1.48 & $5.6 \%$ \\
\hline Aviation & 2.95 & $11.1 \%$ \\
\hline Gasoline/Ethanol & 4.64 & $17.4 \%$ \\
\hline Diesel Oil & 14.62 & $54.8 \%$ \\
\hline TOTAL & 26.67 & $100.0 \%$ \\
\hline
\end{tabular}

Source: Balance Nacional de Energía (Ref. 12)

In summary, a total of $26^{\prime} 666,537 \mathrm{tCO}_{2} / \mathrm{yr}$ are emitted due to the use of fossil fuels in the transportation sector. Nearly $55 \%$ of such emissions come from the use of diesel oil.

\section{ELECTRIC VEHICLES AND POTENTIAL CONTRIBUTION TO CARBON DIOXIDE EMISSIONS REDUCTION}

It is considered that electric vehicles could substitute, under certain circumstances, a few light vehicles that are presently running on fossil fuels. That means that end users may be interested, in the future, in buying electric cars as opposed to cars running on fossil fuels, if purchase prices become reasonable, among other things.

Within the above context, it could be expected that the amount of fuels consumed by vehicles running today on compressed natural gas, liquefied petroleum gas, gasoline motor, and gasoline/ethanol, might be reduced to some extent.

For illustration purposes, substitutions rates of $2 \%, 5 \%$, $3 \%$, and $5 \%$ are considered for CNG, gasoline motor, LPG, and gasoline/ethanol, respectively.

By doing so, $571.1 \mathrm{TJ} / \mathrm{yr}$ of compressed natural gas would not be consumed and thus 32,039 $\mathrm{tCO}_{2} / \mathrm{yr}$ would be avoided. Also, $574.25 \mathrm{TJ} / \mathrm{yr}$ of gasoline motor would not be consumed and thus $39,796 \mathrm{tCO}_{2} / \mathrm{yr}$ would be avoided.
Besides, 705.54 TJ/yr of liquefied petroleum gas would not be consumed and thus $44,496 \mathrm{tCO}_{2} / \mathrm{yr}$ would be avoided. By the same token, 3,349.3 TJ/yr of gasoline/ethanol would not be consumed and $232,106 \mathrm{tCO}_{2} / \mathrm{yr}$ would be avoided. In total, $348,437 \mathrm{tCO}_{2} / \mathrm{yr}$ could be avoided.

This means that a $15 \%$ penetration of electric vehicles would lead to a reduction of $59.70 \%$ when compared to the use of CNG, LPG, Gasoline Motor, and Gasoline/Ethanol, but only a reduction of $0.78 \%$ if compared to total current carbon emissions.

\section{CONCLUSIONS}

The transportation sector is a major source of carbon dioxide emissions. In Peru, several fossil fuels are used for transportation, including compressed natural gas (CNG), liquefied petroleum gas (LPG), gasoline motor, gasoline/ethanol, fuel, oil, and aviation fuel. Also, some electricity is used by a local subway in Lima.

A total of $26^{\prime} 666,537 \mathrm{tCO}_{2} / \mathrm{yr}$ are emitted due to the use of fossil fuels in the transportation sector. Nearly $55 \%$ of those comes from the use of diesel oil.

Electric vehicles may substitute light vehicles that are presently running on fossil fuels. End users may be interested in buying new electric cars instead of cars that are running now on fossil fuels.

If this were case, then it could be expected that consumption of CNG, LPG, gasoline motor, and gasoline/ethanol, may be reduced. Carbon dioxide factor is estimated as $27.0 \mathrm{tCO}_{2} / \mathrm{TJ}$, taking into account that vehicles running on internal combustion engines are less efficient than electric vehicles.

For illustration purposes, substitution rates of $2 \%, 5 \%$, $3 \%$, and $5 \%$ are considered for natural gas, gasoline motor, liquefied petroleum gas, and gasoline/ethanol, respectively.

By doing so, a total of $348,437 \mathrm{tCO}_{2} / \mathrm{yr}$ could be avoided. This means that a $15 \%$ penetration of electric vehicles would lead to a reduction of $59.70 \%$ when compared to the use of CNG, LPG, Gasoline Motor, and Gasoline/Ethanol, but only a reduction of $0.78 \%$ if compared to total current carbon emissions.

Another aspect that may also be considered is that in an initial stage, electric vehicles would most likely replace light vehicle that otherwise would be running on gasoline. However, heavy vehicles would perhaps continue running on diesel oil for a while.

Considering the success of the financial incentives implemented in the past in order to promote the consumption of natural gas by light vehicles, it could also be feasible to design another financial program to facilitate the introduction of electric vehicle under local market conditions.

\section{ACKNOWLEDGMENT}

The authors would like to thank to all the people that, in one way or another, contributed to the present work. 


\section{REFERENCES}

[1] ZHENG Jihu, SUN Xin, JIA Lijie, ZHOU Yan. Electric passenger vehicles sales and carbon dioxide emission reduction potential in China's leading markets. China Automotive Technology and Research Center Co. Tianjin, China, 2020.

[2] KOLBE Karin. Mitigating urban heat island effect and carbon dioxide emissions through different mobility concepts: Comparison of conventional vehicles with electric vehicles, hydrogen vehicles and public transportation. Faculty of Mathematics and Sciences, University of Koblenz, Landau, Germany. 2019.

[3] HOEHNE Christopher, CHESTER Mikhail. Optimizing plug-in electric vehicle and vehicle-to-grid charge scheduling to minimize carbon emissions. Civil, Environmental and Sustainable Engineering, Arizona State University, Tempe, AZ, USA. 2016.

[4] TEIXEIRA Ana, SODRE Jose. Simulation of the impacts on carbon dioxide emissions from replacement of a conventional Brazilian taxi fleet by electric vehicles. Department of Mechanical Engineering, Pontifical Catholic University of Minas Gerais, Belo Horizonte, MG, Brazil. 2016.

[5] TROST Tobias, STERNER Michael, BRUCKNER Thomas. Impact of electric vehicles and synthetic gaseous fuels on final energy consumption and carbon dioxide emissions in Germany based on long-term vehicle fleet modelling. Fraunhofer Institute for Wind Energy and Energy System Technology, Kassel, Germany. 2017.

[6] BROCKDORFF Philip, TANTI Gerald. Carbon emissions of plug-in electric vehicles in Malta: A policy review. University of Malta, Malta. 2017.

[7] MORO Alberto, LONZA Laura. Electricity carbon intensity in European Member States: Impacts on GHG emissions of electric vehicles. European Commission, Joint Research Centre (JRC), Ispra (VA), Italy. 2018.

[8] REQUIA Weeberb, ADAMS Matthew, ARAIN Altaf, KOUTRAKIS Petros, FERGUSON Mark. Carbon dioxide emissions of plug-in hybrid electric vehicles: A life-cycle analysis in eight Canadian cities. McMaster University, McMaster Institute for Transportation and Logistics, Ontario, Canada. 2017.

[9] KÜFEOLU Sinan, HONG Dennis. Emissions performance of electric vehicles: A case study from the United Kingdom. Judge Business School, University of Cambridge, United Kingdom. 2020.

[10]AMBROSE, Hanjiro, KENDALL Alissa, LOZANO Mark, WACHCHE Sadanand, FULTON Lew. Trends in life cycle greenhouse gas emissions of future light duty electric vehicles. Department of Civil and Environmental Engineering, University of California, Davis, USA. 2020.

[11]INTERNATIONAL PANEL ON CLIMATE CHANGE. Guidelines for National Greenhouse Gas Inventories. Tokyo, Japan. 2006.

[12]MINISTRY OF ENERGY AND MINES. Balance Nacional de Energía. Lima, Peru. 2017

$1^{\text {th }}$ LACCEI International Multi-Conference for Engineering, Education, and Technology: "Engineering, Integration, and Alliances for a Sustainable Development" "Hemispheric Cooperation for Competitiveness and Prosperity on a Knowledge-Based Economy", 29-31 July 2020, Buenos Aires, Argentina. 